\title{
Social Accountability: Impact on the Medical Staff \& Medical Initiatives in the Neglected Areas
}

\author{
Bishara Bisharat ${ }^{1}$, Yousif Nijim ${ }^{2}$, Samar Samawi $^{3}$ and Abdalla Bowirrat ${ }^{4}$ \\ 1. Department of Family Medicine, Director of EMMS Nazareth, University of Bar Ilan, Nazareth 16100, Israel \\ 2. Department of Pediatric and Neonatal, EMMS Nazareth Hospital, University of Bar Ilan, Nazareth 16100, Israel \\ 3. Department of Family Medicine, EMMS Nazareth Hospital, University of Bar Ilan, Nazareth 16100, Israel \\ 4. Department of Clinical Neuroscience, Neuropsychopharmacology \& Population Genetics, EMMS Nazareth Hospital, University \\ of Bar Ilan, Nazareth 16100, Israel
}

\begin{abstract}
INTRODUCTION: In 1861, Doctor Kaloost Vartan arrived in Nazareth, and set up a dispensary that was the only "hospital" between Jerusalem, Damascus and Beirut. For 153 years, The Nazareth Hospital aims to extend health care to all, in a spirit of reconciliation between people: Jews and Arabs, Christian, Muslims and Druze. The hospital staff in the early years of the 19th century initiated mobile clinics to serve the unreached areas that lack health services. Also the model of mother and child community clinics that the hospital staff initiated in 1950s was adopted by the Israeli ministry of health and has been implemented as part of the ministry's service to mother and child. PURPOSE/METHODS: Since 2012, the hospital management decided to have the community involvement as part of the hospital strategy, social accountability was one of the hospital torches of the hospital work. One of the major projects that are under the social accountability work is providing medical services to the neglected areas in the West Bank Area C. For this purpose, hospital staff visited the area and met key persons in Ein Baida a small village in Tobas district to examine the population health care need. RESULTS: The hospital staff opened a medical center which medical tests for 70 children, and pediatricians started a clinic in a weekly basis. Later on, more services were given to Palestinians Bedouin area-Al Maleh-that their population lives in tents with their own animals and lacks of clean source of water and electricity, a place with an urgent need for medical services. CONCLUSIONS: Our mission started with few doctors' involvement, and today tens of hospital staff provides medical services, in addition to donations that the staff sent to the population. The social accountability and reaching the neglected, is also a great tool to encourage staff communicate with others that are ambitious and care about the community, build self-esteem and self-confidence, and meet new people.
\end{abstract}

Key words: Social accountability, neglected areas, west bank, health care, hospital staff.

\section{Introduction}

Despite the high level of interest in social accountability initiatives, there is no full agreement or consensus on a common definition of what really it is. Plethora of definitions exist; for instance, the responsibility of a person of a power-holders to account for their activities, their actions, accept responsibility for them, and to disclose the results in a transparent manner [1].

Social accountability (SA), is the measures that are made by an institute to be observant of concerns to the

Corresponding author: Bowirrat Abdalla, M.D., Ph.D., professor, research field: neuroscience. community neighboring it. It is contemplated in an obligation to health and safety, civil and human rights and improvement of the community. Broadly speaking, social accountability (SA) encompasses almost all citizens, institutions and organization engagement activity, particularly including both involvement in deliberative decision-making and participation in accountability [1-4].

Indeed, SA complements and strengthens the capacity of citizens and the private sector to hold authorities accountable for better development results and encourage interventions by the government's representatives to provide civil service reform, public 
financial management, and strengthening of public accountability institutions. By bringing together the spheres of public participation, citizen rights, and public sector reform, SA puts people at the center of the governance agenda [5].

Other features of SA describes the dynamics of rights and responsibilities that exist between people and the institutions that have an impact on their lives, in particular the relationship between the duties of the state and the entitlements of citizens. Thus, accountability is a corner stone and one of the foundations of democracy, rights-based governance and equitable human development.

The value of accountability springs from its power to measure whether the relationship between the state and citizens is built upon sincerity, honesty and justice or not. This relationship between state and the inclusive society should be established on a social contract between both sides and should ensure the full rights of the minorities, poorest and most marginal division of the society. Such contracts "have to be build eventually, through reciprocal interactions between states and citizens" [5].

Benefits of SA as an approach to governance comes from involvements of the general public and civil society in public decision making. These interventions help the citizen and civil society to articulate their needs to government and service providers. The result of this involvement will likely come into play in measuring progress in human rights, good governance, inequalities and environmental protection.

Social accountability is based on three key doctrines: Transparency, accountability and participation. The success of these values depends on several circumstances, such as: the need for an adequate political environment, for civic engagement and a suitable policy and legal framework in addition to capable and supportive state actors, and the institutional capabilities of non-state actors.

\section{Purpose/Aims of This Study}

Herein, we will shed light on one of the plentiful engagements of the Edinburgh Medical Missionary Society (EMMS) Hospital in Nazareth in social activities as part of the hospital health strategy. Historically, in 1861, Doctor Kaloost Vartan arrived in Nazareth, and build up a dispensary that was the only "hospital" between Jerusalem, Damascus and Beirut which gave medical services for all population stratums in the area. After more than 153 years, the hospital is still carrying the flag to provide the best health care to all population as part of its ambition, and in a spirit of reconciliation between people whatever their religious affiliation and ethnic background.

Indeed, the EMMS Hospital is passionately committed to community wellness, driven and enabled by dedicated, innovative physicians, staff and leadership in a spiritual environment.

Since 2012, and despite the countless challenges and the insufficient financing, the hospital management decided to continue the ongoing implementation of health policy by involvement and providing a health care to the community as part of the hospital strategy, thus, social accountability was one of the torches of the hospital work. Actually, one of the major projects that are taking place under the social accountability is providing medical services to the neglected areas located in the Palestinian authority (West Bank Area C). For this purpose, our hospital staff visited the area and met key persons in Ein Baida a small village in Tobas district, to examine the population needs. Various medical activities had been done, in addition, health promotion activities, health education seminars were performed, approaches to tackle chronic diseases and the strategies of prevention were also discussed widely. We recommended the population to change life style tradition, avoiding sedentary life style by increasing sport activity, encouraging and emphasizing the use of whole wheat bread and flour, raising awareness about diabesity, and initiating leadership training for community health workers to trigger them lead the change and "fight" obesity and diabetes. 


\section{Results of Our Intervention}

During our recursively visits to the neglected area (Ein Baida a small village in Tobas), our staff decided to open a small medical center that is still under construction. Comprehensive medical tests for 70 children were done, and pediatricians started a clinic in a weekly basis. Later on, more medical services, equipments and supplies were given to the Palestinian Bedouin area-Al Maleh that was destroyed during 1967, today with a Population of 4000, that lives in tents with their own animals and lacks of clean source of water and electricity, a place with an urgent need for medical services. During our activity, a survey was held among our hospital staff in that area, to examine the accountability, efficiency and the helpfulness of our hospital social activities: the results of that survey were encouraging and showing that: (1) All of the hospital staffs in the neglected areas in the West Bank Area C, heard about our hospital social accountability and health promotion activities (100\% helpful); (2) All the participants in the survey said that these activities are very important, and vital: $57.9 \%$ versus $42.1 \%$ respectively; (3) The hospital staffs in the neglected areas in the West Bank were involved in some way (47.4\%); (4) All of those involved mentioned that these activities had added value to them personally (Fig. 1).

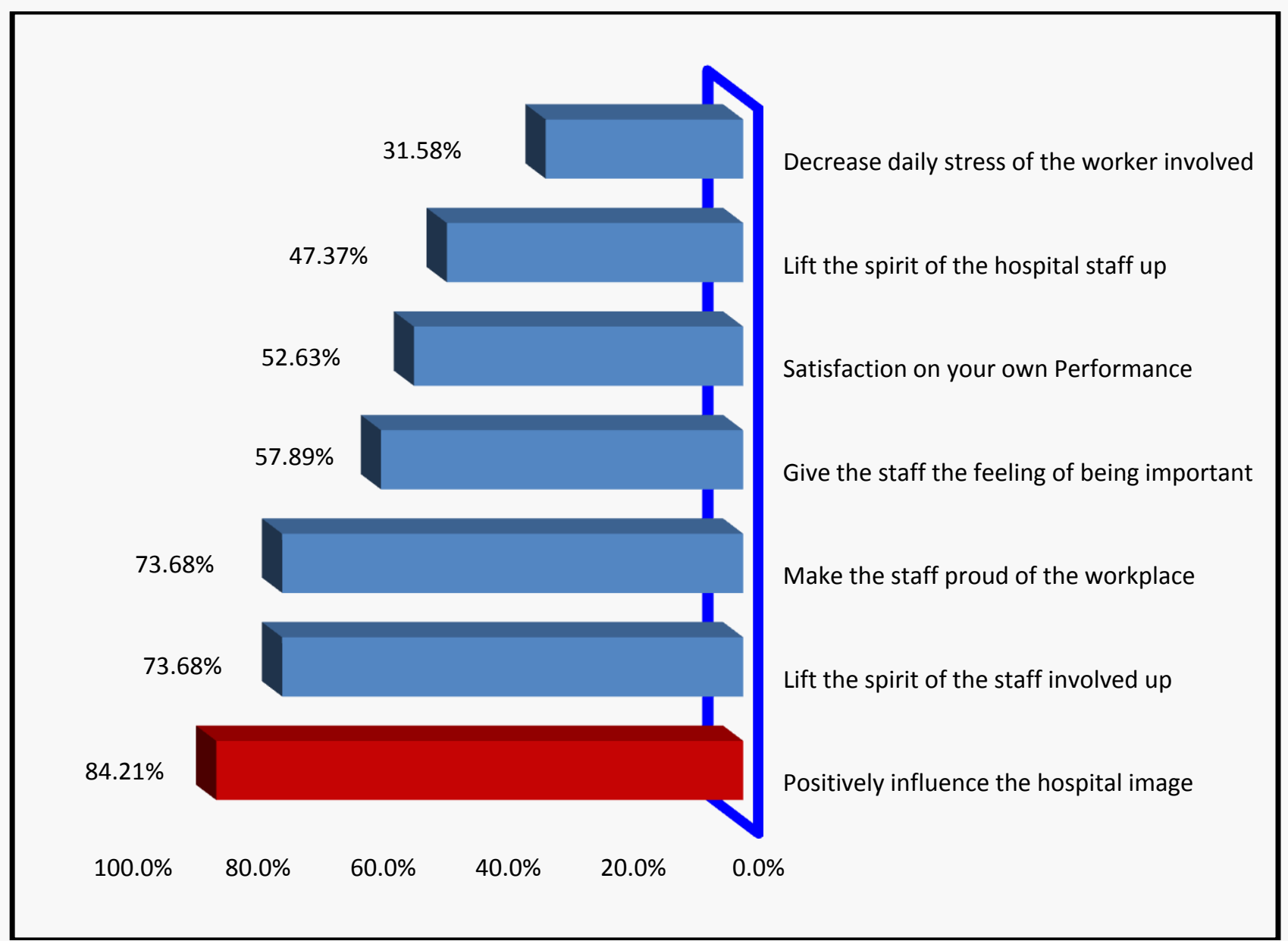

Fig. 1 Social accountability exams, efficiency and the helpfulness of our hospital social activities. 


\section{Conclusions}

In the current context of social accountability, the time is ripe to reflect on lessons from the various initiatives and ask how they can further support positive changes in our communities.

Community involvement is one of the top priority and part of our hospital strategy since its foundation, and social accountability is considered as part of the hospital values. These values are also carved in the hearts of our crew and trigger our staffs to initiate a community involvement activity even far away from our hospital, in the neglected occupied Palestinian territory. Social accountability initiatives tend to be especially used in areas of precarious statehood, because of the inadequacy of formal structures of governance [6].

However, our mission started with few doctors' involvement, and today many of our hospital staff provides medical services in addition to various humanitarian aids collected and distributed to the population. The social accountability and reaching the neglected areas in west bank, is in itself one of the great methods to encourage staff to communicate with others that are ambitious and care about the community, build self-esteem and self-confidence, and meet new people. In addition the staff appreciates more the hospital, something that can motivate them in their daily work in the hospital.

In fact, in areas of insecurity, people withdraw into the private sphere and adopt resiliency and survival mechanisms; therefore, support to this community's health care will be essential to increase the citizen empowerment of poor people, including increased awareness of their general health. Flexible and innovative programming that addresses the needs of the neglected population will have a great impact on various levels. Moreover, social accountability will lead to increased responsiveness and subsequently improved public health services.

\section{Acknowledgments}

The authors would like to thank Miss Aia Bowirrat for her contribution in revising and editing the study.

\section{References}

[1] Malena, C. R., and Singh, J. 2004. "Social Accountability: An Introduction to the Concept and Emerging Practice." In Social Development Papers. Washington D.C.: The World Bank.

[2] Malena, C. R., and Singh, J. 2004. "The Role of Civil Society in Holding Government Accountable: A Perspective from the World Bank on the Concept and Emerging Practice of "Social Accountability"." In Social Development Paper. Washington, D.C.: The World Bank.

[3] Arroyo, D. 2005. "Stocktaking of Social Accountability Initiatives in the Asia and Pacific Region." In World Bank Institute Working Papers. Washington D.C.: The World Bank.

[4] Kabeer, N. 2000. "Social Exclusion, Poverty and Discrimination: Towards an Analytical Framework." IDS Bulletin 31 (4): 83-97.

[5] McGee, R., and John, G. 2011. "Shifting Power? Assessing the Impact of Transparency and Accountability Initiatives." IDS Working Paper 2011: 1-39.

[6] McNeil, M., and Carmen, M. 2010. Demanding Good Governance: Lessons from Social Accountability Initiatives in Africa, Chapter 6 Gender Sensitive and Child-Friendly Budgeting in Zimbabwe. Washington DC: World Bank. 